\title{
D-lactoacidosis como Complicación del Síndrome de Intestino Corto
}

\author{
GABRIEL ARANCIBIA A. ${ }^{1}$, MARÍA ISABEL HODGSON B. ${ }^{1}$, PAUL R. HARRIS D. ${ }^{1}$
}

1. Unidad de Gastroenterología y Nutrición Pediátrica, Departamento de Pediatría, Facultad de Medicina, Pontificia Universidad Católica de Chile.

\begin{abstract}
\section{D-lactoacidosis as Short Bowel Syndrome Complication}

Short bowel syndrome is defined as the loss, congenital or acquired, anatomical or functional, of a large part of the small intestine that generates inadequate absorption of nutrients and the frequent need of prolonged parenteral nutrition. The etiology of short bowel is diverse and varies with age. The necrotizing enterocolitisis and the midgut volvulus are among the most frequent causes. The bacterial overgrowth is frequently observed in children with short bowel, due to the secondary dilation of the remaining small bowel and to the associated intestinal dysmotility. It is more frequent in absence of the ileocecal valve. We present a 6 year old boy with short bowel syndrome secondary to extensive intestinal resection after a volvulous of the medium small intestine, 9 months before admission to the hospital, and who was on cyclical parenteral nutrition at home. The child developed ataxia, disarthria, dizziness and conscience compromise been admitted to de intensive care unit in deep sopor. An extensive work up including metabolic, infectious, toxicology and SNC imaging was negative except for metabolic acidosis. He was discharged on good conditions. Even though the child was on supportive therapy, the patient was readmitted few hours later with similar symptoms. D-lactoacidosis was suspected and confirmed with a value of $6.69 \mathrm{mmol} / \mathrm{l}$ (normal range: $0,0-0,25$ ). Literature about this uncommon complication and its mechanism is reviewed. D-lactoacidosis should be suspected in every patient with short bowel syndrome and unexplained metabolic acidosis associated with neurologic symptoms.
\end{abstract}

(Key words: short bowel, D-lactic acidosis, parenteral nutrition).

Rev Chil Pediatr 2010; 81 (4): 353-357

\section{RESUMEN}

El síndrome de intestino corto se define como la pérdida, congénita o adquirida, anatómica o funcional, de una extensa área del intestino delgado que genera inadecuada absorción de nutrientes y la frecuente necesidad de nutrición parenteral prolongada. Su etiología varía con la edad. Entre las causas más frecuentes están la enterocolitis necrotizante y el vólvulo de intestino medio. El sobrecrecimiento bacteriano es frecuente en estos pacientes, debido a la dilatación secundaria del remanente de intestino delgado y a la dismotilidad intestinal asociada. Objetivo: Comunicar un caso de acidosis D-láctica en un niño con Intestino corto. Caso clínico:

Trabajo recibido el 17 de febrero de 2010, devuelto para corregir el 15 de marzo de 2010, segunda versión el 06 de abril de 2010, aceptado para publicación el 08 de abril de 2010.

Correspondencia a:

Dr. Gabriel Arancibia A.

E-mail: sarancib@med.puc.cl 
Niño de 6 años con antecedente de intestino corto secundario a resección intestinal por vólvulo de intestino medio 9 meses previos al ingreso y que estaba recibiendo nutrición parenteral domiciliaria ciclada. El niño desarrolló ataxia, disartria, mareos y compromiso de conciencia, ingresando a la unidad de cuidados intensivos en sopor profundo. Un extenso estudio metabólico, infectológico, toxicológico y de neuroimágenes fue negativo, excepto por acidosis metabólica. Fue dado de alta en buenas condiciones. A pesar del tratamiento de soporte vuelve a ingresar horas después con similar cuadro clínico. Se sospecha y confirma elevación de Dlactato en sangre $(6,69 \mathrm{mmol} / 1$ con rango normal de $0,0-0,25)$. Se revisa la literatura acerca de esta infrecuente complicación y su mecanismo de producción. La D-lactoacidosis debiera ser sospechada en todos los pacientes portadores de intestino corto que presenten un cuadro de acidosis metabólica no explicada, especialmente si se acompaña de compromiso de conciencia y síntomas cerebelosos.

(Palabras clave: intestino corto, D-lactoacidosis, nutrición parenteral).

Rev Chil Pediatr 2010; 81 (4): 353-357

\section{Introducción}

Las causas de intestino corto son múltiples y varían de acuerdo con la edad. Los más afectados son los neonatos, en especial los prematuros. Entre las causa perinatales destacan las malformativas como las atresias intestinales y la gastrosquisis. Desde el período neonatal predomina el vólvulo de intestino medio y la enterocolitis necrotizante. Otras causas son la trombosis arterial o venosa intestinal, la invaginación intestinal complicada y la enfermedad de Hirschsprung extensa o total.

Los niños con intestino corto requerirán nutrición parenteral por un período prolongado de tiempo. La adaptación intestinal se caracteriza por la dilatación y disminución del peristaltismo del intestino remanente, lo que aumenta su capacidad absortiva, pero a la vez favorece el sobrecrecimiento bacteriano.

Dentro de las complicaciones posibles del intestino corto figura la D-lactoacidosis. Para que se produzca un acúmulo de ácido D-láctico en sangre se requiere que exista una alteración de base que permita una sobrecarga de hidratos de carbono al colon y una flora intestinal, normal o aumentada, productora de D-lactato. La capacidad del ser humano para metabolizar el D-lactato es limitada por lo que una absorción significativa desde el colon lleva a una acidosis metabólica. Estas condiciones están presentes en el intestino corto.

Los seres humanos sólo sintetizan mínimas cantidades de D-lactato por la vía endógena de la metilglioxilasa. Los niveles de D-lactato en sangre superiores a $0,25 \mathrm{mmol} / \mathrm{l}$ son siempre patológicos y pueden deberse a la producción bacteriana a nivel del tracto digestivo, a la ingesta o a la administración parenteral a través de soluciones de ringer lactato o de peritoneodiálisis. La primera descripción publicada de D-lactoacidosis en humanos fue en el año $1979^{1}$. El primer caso pediátrico fue publicado al año siguiente ${ }^{2}$.

El objetivo de este trabajo es comunicar un caso de acidosis D-láctica en un niño con intestino corto y alertar sobre la necesidad de sospechar y buscar esta complicación metabólica en todo paciente portador de intestino corto que presente un cuadro de acidosis metabólica de etiología no explicada, especialmente si se acompaña de compromiso de conciencia y síntomas cerebelosos ${ }^{3,4}$.

\section{Caso clínico}

Niño de 6 años con antecedente de haber requerido una resección amplia de intestino delgado con un remanente de $40 \mathrm{~cm}$ de yeyuno y $10 \mathrm{~cm}$ de ileon terminal con preservación de válvula ileocecal, debido a un vólvulo de intestino medio nueve meses previo a su ingreso. Tres semanas después de la operación se determinó, en un examen radiológico de tránsito intestinal, que su remanente de intestino delgado era de $25 \mathrm{~cm}$. En el transcurso de su evolución alcanza una condición estable recibiendo nutrición parenteral domiciliaria ciclada con cambio reciente de 5 a 3 veces por 
semana. Una semana previo a su ingreso destacaba un buen estado nutricional con un índice de masa corporal de 18,4 y un índice peso/talla de $119 \%$. En los últimos tres meses el niño no había requerido antibioterapia y recibía tratamiento habitual con omeprazol $20 \mathrm{mg}$ y hierro elemental $30 \mathrm{mg}$ al día. La ingesta oral previa a este cuadro consistía en fórmula polimérica sin lactosa y dieta pobre en residuos, baja en grasa y $\sin$ restricción mayor de carbohidratos.

El cuadro clínico se inició 2 días previos a su ingreso, caracterizado por decaimiento e inapetencia. Al día siguiente se agregó ataxia y compromiso de conciencia, inicialmente oscilante, lo que motivó su consulta al servicio de urgencia donde llegó en buenas condiciones, bien hidratado y habiendo presentado mejoría espontánea. No se realizaron exámenes en ese momento y fue enviado a su casa con indicaciones de volver a consultar si los síntomas reaparecían. Horas más tarde el niño presenta nuevamente ataxia y compromiso de conciencia, sumándose disartria, mareos y vómitos por lo que se decide su hospitalización.

El niño ingresa a la unidad de cuidados intensivos en sopor profundo. En sus exámenes de laboratorio destaca un $\mathrm{pH}$ de 7,22, un bicarbonato de 14,2 mEq/1 y un exceso de base de $-14 \mathrm{mEq} / 1$. Los electrolitos plasmáticos, el L-lactato, el amonio, el hemograma y el perfil bioquímico fueron normales. El estudio toxicológico (toxilab ${ }^{\circledR}$ ) fue negativo. El electroencefalograma y la resonancia nuclear magnética de encéfalo fueron normales.

Corregida su alteración ácido-base, desaparecieron el compromiso de conciencia y los síntomas cerebelosos. El niño evolucionó favorablemente y se decidió dar de alta a las 48 horas de su ingreso con control ambulatorio. Se postuló retrospectivamente una D-lactoacidosis como causa probable de su cuadro clínico y se solicitó tomar muestra en fase crítica de acidosis para análisis de D-lactato en sangre si el cuadro se volvía a presentar.

Doce horas después de su egreso el niño volvió a consultar en el servicio de urgencia por cuadro de compromiso de conciencia, ataxia y disartria. En sus exámenes destacó un $\mathrm{pH}$ en sangre de 7,23 con bicarbonato de $15,3 \mathrm{mEq} / 1$ y exceso de base de $-12 \mathrm{mEq} / \mathrm{l}$. El
L-lactato, el amonio, los electrolitos, el calcio $\mathrm{y}$ el fósforo plasmáticos fueron nuevamente normales. Entre los antecedentes recabados en esa oportunidad, destacaba que en las horas previas el niño había consumido cereales y otros alimentos ricos en carbohidratos simples. Se tomó muestra para análisis de D-lactato y se envió al laboratorio de la Clínica Mayo en EEUU.

Ante la sospecha de D-lactoacidosis, se decidió mantener al paciente en ayunas por 72 horas con realimentación progresiva, pobre en azúcares refinados. Se indicó antibioterapia biasociada de metronidazol-ciprofloxacino. El niño evolucionó favorablemente y fue dado de alta con indicación de completar 7 días de terapia antibiótica, continuando luego con terapia probiótica por 7 días con Lactobacillus casei variedad rhamnosus.

Ocho días después se recibió el resultado del análisis de D-lactado en sangre que fue $6,69 \mathrm{mmol} / 1$ con un rango normal de $0,0-0,25$, lo que confirmó el diagnóstico.

En los meses siguientes al alta el niño se mantuvo con nutrición parenteral 5 días a la semana, restricción de carbohidratos simples en la alimentación oral y tratamiento intermitente con Metronidazol y Lactobacillus casei.

La evolución clínica ha sido satisfactoria, no ha vuelto a presentar síntomas neurológicos y el control seriado de gases en sangre no ha mostrado acidosis metabólica, lo que ha permitido seguir avanzando en la alimentación oral y suspender progresivamente la nutrición parenteral.

\section{Discusión}

El L-lactato es el isómero del lactato producido en el metabolismo humano. Las bacterias intestinales al metabolizar los hidratos de carbono producen L-y D-lactato. Los laboratorios clínicos habituales sólo miden L-lactato, por lo que la determinación de $\mathrm{D}$-lactato requiere de un laboratorio especializado.

La D-lactoacidosis es una causa inusual de acidosis. Para que ésta se genere se requiere: a) una malabsorción subyacente de carbohidratos en el intestino delgado que provoque una carga aumentada de éstos al colon; b) la consiguiente 
metabolización de los hidratos de carbono no absorbidos por la flora intestinal a D-lactato; c) la absorción y acúmulo en sangre del Dlactato debido a que la metabolización del Dlactato en seres humanos es poco eficiente. Se produce así una acidosis metabólica con anión gap aumentado y L-lactato normal ${ }^{5}$.

Casi siempre la D-lactoacidosis se presenta con manifestaciones neurológicas acompañantes aunque éstas tienen una gran variabilidad en intensidad, que es paciente dependiente. Es frecuente hallar disartria, confusión, incapacidad de concentrarse, somnolencia, alucinaciones, torpeza, debilidad, ataxia, marcha inestable, nistagmo, irritabilidad y alteraciones conductuales ${ }^{6}$. Por ello siempre debiera sospecharse una D-lactocidosis en todo paciente portador de intestino corto que presente síntomas neurológicos de causa no precisada ${ }^{7}$.

El D-lactato, isómero óptico del L-lactato, detectable en fluidos humanos tiene como origen la producción bacteriana a nivel del tracto intestinal, la ingestión de D-lactato o la producción endógena por la vía de la metilglioxilasa ${ }^{8}$. La producción y metabolismo del L-lactato requiere la enzima L-lactato deshidrogenasa. Para D-lactato se requiere de la D-lactato deshidrogenasa. Después de la absorción de ambos isómeros sólo el D-lactato se acumula debido a su metabolismo más lento por carencia de la enzima ${ }^{9}$ y a su menor depuración renal ${ }^{10}$. En el ser humano, carente de D-lactato deshidrogenada, es la enzima D-2-hidróxido deshidrogenasa la que convierte el D-lactato en piruvato. Esta enzima se encuentra presente en el hígado, riñón y páncreas humanos, pero no es capaz de metabolizar eficientemente una carga alta de D-lactato y evitar que éste se acumule en sangre (figura 1).

El ácido D-láctico es un ácido orgánico de bajo peso molecular que luego de ser absorbido se acumula hasta ser excretado inalterado en la orina. La D-lactoacidosis es la consecuencia de esta acumulación en el plasma. Para que esto se produzca debe existir de base un intestino corto. En esta situación clínica se produce una sobrecarga colónica de carbohidratos no absorbidos que son fermentados por la flora colónica produciendo ácidos orgánicos. Se produce entonces una progresiva disminución del $\mathrm{pH}$ luminal lo que altera el microambiente favoreciendo el sobrecrecimiento de Lactobacillus acidophilus, Lactobacillus fermenti y estreptococo. Estas son las principales bacterias

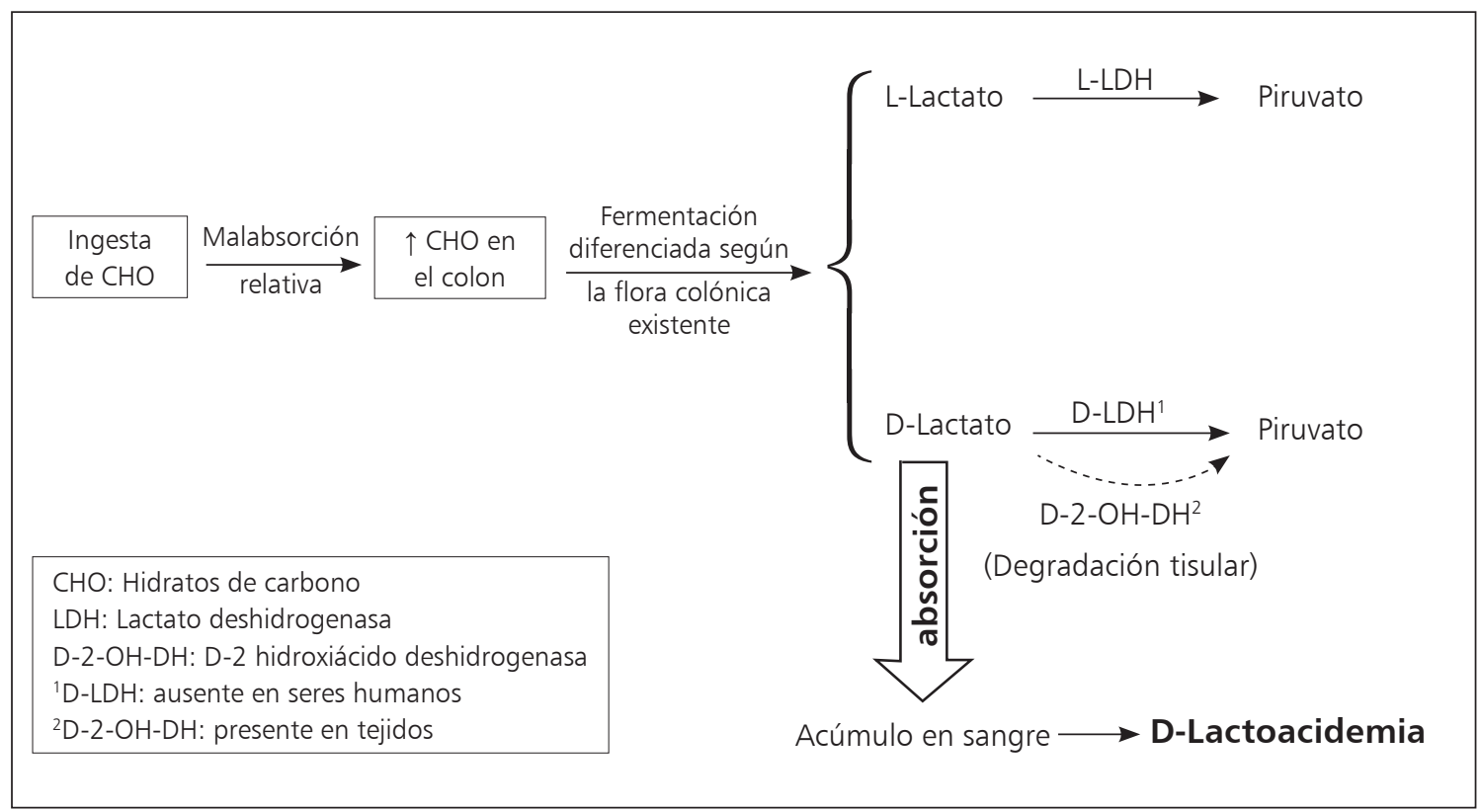

Figura 1. Mecanismo de desarrollo de la D-Lactoacidemia. 
productoras de D-lactato ${ }^{11}$. Además, en estas condiciones la flora intestinal muestra una preponderancia de anaerobios Gram positivo que son los mayores productores de lactato. Una motilidad colónica disminuida favorece la fermentación bacteriana de los carbohidratos no absorbidos ${ }^{4}$, así como la deficiencia de tiami$\mathrm{na}^{12}$.

El motivo por el cual la D-lactoacidosis produce manifestaciones neurológicas no es explicable sólo por la acidosis en sí misma pues pacientes que presentan otros tipos de acidosis de severidad comparable no presentan estos síntomas. Es posible que el D-lactato sea tóxico para el cerebro. Al parecer el cerebro carece de la D-2-hidróxido deshidrogenasa por lo que el D-lactato tendría una excesiva acumulación local y alteraría el $\mathrm{pH}$ intraneuronal. El pH bajo inhibe la decarboxilación del piruvato al alterar el funcionamiento de la piruvato deshidrogenada y por tanto disminuye la producción de acetil CoA y adenosintrifostato, lo que alteraría la producción de neurotransmisores. Debido a que el cerebelo contiene mínimas reservas de piruvato deshidrogenasa, las manifestaciones cerebelosas suelen ser prominentes en la D-lactoacidosis ${ }^{13}$.

El tratamiento de la D-lactoacidosis se basa en corregir la acidosis metabólica, disminuir la cantidad de sustrato para la fermentación bacteriana intestinal restringiendo el aporte de carbohidratos, y administrar por vía oral antibióticos idealmente no absorbibles ${ }^{14,15}$. Existe una gran diversidad de esquemas propuestos en la literatura. Coinciden en la necesidad de tratamiento cíclico para evitar la recurrencia, por ejemplo los primeros 5 a 7 días de cada mes, variando el antibiótico utilizado cada 3 a 4 meses para evitar la selección de cepas resistentes. Para prevenir las recurrencias es necesario además el uso prolongado de una dieta limitada en carbohidratos. Luego de la antibioterapia se ha recomendado también el uso de probióticos como Lactobacillus casei y/o Bifidobacterium brebe, productores sólo de Llactato ${ }^{14}$, aunque la indicación sistemática de probióticos en estos pacientes es un tema aún controvertido.

\section{Referencias}

1.- Oh MS, Phelps KR, Traube M, et al: D-lactic acidosis in a man with the short-bowel syndrome. N Engl J Med 1979; 301: 249-52.

2.- Schoorel EP, Giesberts MA, Blom W, van Gelderen HH: D-Lactic acidosis in a boy with short bowel syndrome. Arch Dis Child 1980; 55: 810-2.

3.- Soler P, Garzón P, Castilla Y, et al: D-lactic acidosis in an 11-year-old patient with short bowel syndrome. Ann Pediatr (Barc) 2006; 64: 385-7.

4.- Dahhak S, Uhlen S, Mention K, et al: D-lactic acidosis in a child with short bowel syndrome. Arch Pediatr 2008; 15: 145-8.

5.- Vella A, Farrugia G: D-lactic acidosos. Pathologic consequence of saprophytism. Mayo Clin Proc 1998; 73: 451-6.

6.- Uribarri J, Oh MS, Carroll HJ: D-lactic acidosis: A review of clinical presentation, biochemical features, and pathophysiologic mechanisms. Medicine 1998; 77: 73-82.

7.- Godey F, Bouasria A, Ropert M, et al: Don't forget to test for D-lactic acid in short-bowel syndrome. Am J Gastroenterol 2000; 95: 3675-77.

8.- Thornalley PJ: Pharmacology of methylglyoxal: formation, modification of proteins and nucleic acids, and enzymatic detoxification-a role in pathogenesis and antiproliferative chemotherapy. Gen Pharmacol 1996; 27: 565-73.

9.- Tubbs PK: The metabolism of $\mathrm{D}-\alpha$-hydroxy acids in animal tissues. Ann N Y Acad Sci 1965; 119: 920-6.

10.- De Vrese M, Koppenhoefer B, Barth CA: D-lactic acid metabolism after an oral load of DL-lactate. Clin Nutr 1990; 9: 23-8.

11.- Anonymous: The colon, the rumen, and D-lactic acidosis [editorial]. Lancet 1990; 336: 599-600.

12.- Hudson M, Pocknee R, Mowat NA: D-lactic acidosis in short bowel syndrome-an examination of possible mechanisms. Q J Med 1990; 74: 157-63.

13.- Cross SA, Callaway CW: D-lactic acidosis and selected cerebellar ataxias. Mayo Clin Proc 1984; 59: 202-5.

14.- Uchida H, Yamamoto H, Kisaki Y, et al: D-Lactic Acidosis in Short-Bowel Syndrome Managed With Antibiotics and Probiotics. J Pediatr Surg 2004; 39: 634-36.

15.- Bongaerts GP, Tolboom JJ, Naber AH, et al: Role of bacteria in the pathogenesis of short-bowel syndromeassociated D-lactic acidemia. Microb Pathog 1997; 22: 285-93. 